Original article

\title{
Tear and serum superoxide dismutase and catalase activities in hypertensive retinopathy
}

\author{
Ecaterina Pavlovschi ${ }^{1}$, Valeriana Pantea ${ }^{1}$, Djina Borovic ${ }^{2}$, Olga Tagadiuc ${ }^{1}$ \\ ${ }^{1}$ Nicolae Testemitanu State University of Medicine and Pharmacy, Chisinau, Moldova \\ ${ }^{2}$ Ovisus Medical Private Center, Chisinau, Moldova
}

Received 17 September 2020, Revised 23 April 2021, Accepted 26 April 2021

(C) 2020, Russian Open Medical Journal

\begin{abstract}
The objective was to determine the changes in SOD and catalase activity, markers of oxidative stress/antioxidant balance in serum and tear of patients with hypertensive retinopathy and to identify whether there was a correlation between their levels and HR degree of hypertensive retinopathy (HR).

Material and Methods - 90 hypertensive patients were divided in three groups, according to the Keith-Wagener classification: GI-36, GII35 and GIII-19. SOD was assessed using the Dubinina and Matyushin method and catalase according to Koroliuk, both in modification of Gudumac V. The results were presented by median and interquartile range. The groups were compared using Kruskal-Wallis and MannWhitney nonparametric tests, and the Spearman correlation coefficient was calculated (SPSS 23.0).

Results - Showed a statistically significant difference of SOD in serum $(p=0.035)$ and tear $(p=0.027)$ between groups. SOD decreased from GI until GIII in serum $(-8 \%, p=0.032)$ and tear $(-16 \%, p=0.031)$. In addition, it showed a weak significant negative correlation with the HR degree both in serum $(r=-0.246, p=0.019)$ and tear $(r=-0.284, p=0.007)$, while the correlation attested between serum and tear SOD levels was significant moderate and positive $(r=0.336, p=0.001)$. It was noted a significant catalase elevation in the tear $(p=0.033)$. In serum it was not correlated with HR degree, while in tear showed a significant weak strength, positive correlation $(r=0.261, p=0.013)$. No correlations were found between serum and tear catalase levels.

Conclusion - A progressive significant decrease in SOD levels and a tendency to increase of catalase activity was identified as HR advanced both in serum and in tear. The enhancement in the severity of HR was correlated with decreased SOD activity in tear and serum and increased catalase level in tear.
\end{abstract}

Keywords: superoxide dismutase, catalase, oxidative stress, antioxidant system, hypertensive retinopathy.

Cite as Pavlovschi E, Pantea V, Borovic D, Tagadiuc O. Tear and serum superoxide dismutase and catalase activities in hypertensive retinopathy. Russian Open Medical Journal 2021; 10: e0305.

Correspondence to Ecaterina Pavlovschi. Address: Department of Biochemistry and Clinical Biochemistry, Nicolae Testemitanu State University of Medicine and Pharmacy, 165, Stefan cel Mare si Sfant ave, Chisinau, Republic of Moldova, MD-2004. Phone: +37379571092. E-mail: ecaterina.pavlovschi@usmf.md.

\section{Introduction}

Systemic arterial hypertension (HTN) is a major public health issue that is associated with an elevated risk of cardiovascular, cerebrovascular, renal and retinal disorders [1]. WHO estimated that worldwide 1.13 billion people have HTN and less than 1 in 5 from them have the condition under control [2].

Hypertensive retinopathy (HR) is a series of retinal microvascular changes caused by elevated uncontrolled blood pressure and is the most common ocular complication [1]. In a study by Erden et al. was proved that the severity and duration of HTN are directly proportional to the incidence of HR, which ranges from $66.3 \%$ to $83.6 \%$ out of the total hypertensive subjects [3-5].

The main danger of HTN and of HR itself, lies in the lack of prevenient symptoms. This is one of the reasons why an asymptomatic hypertensive patient can in many instances be primarily diagnosed with $\mathrm{HR}$ at a random visual check and only at that point referred to a general practitioner. Moreover, based on the high prevalence of uncontrolled HTN, hypertensive subjects must be aware of the fact that a successful treatment and an in- time diagnosis of HTN reduces the risk of HR development and of vision disorders [6-8].

An ophthalmological consultation relies on the eye specialist's dexterity, being in many ways subjective. Along these lines, the biochemical markers are demanded as an extra help in the estimation of HR degree and a subsequent correct treatment approach.

Oxidative stress (OS) and inflammation are regarded as HR prime reasons, but remained underexamined. The retina was always an attractive tissue for investigation, being a complex highly metabolic organ that works entirely by aerobic respiration, consuming the highest amount of oxygen in comparison with any other tissue. A consequence of this fact, will result in generation of reactive oxygen species (ROSs), like superoxide $\left(\mathrm{O}_{2}^{-} \mathbf{9}\right.$, hydroxyl radical $(\bullet \mathrm{OH})$, and hydrogen peroxide $\left(\mathrm{H}_{2} \mathrm{O}_{2}\right)[9]$.

The pathogenetic role of only two markers of OS were investigated in HR: serum gamma-glutamyl transferase (GGT) and serum ferritin levels. Both of these markers demonstrated a notable enhancement in their levels in parallel with the HR 
progression and also displayed a positive correlation with the grade of HR $[9,10]$.

Under physiological conditions, the harmful effects of ROSs can be kept under control by a series of antioxidant proteins. Superoxide dismutase (SOD), whose isoforms can be differentiated by their localization and metallic constituents, acts like a primary defense mechanism against free radicals by catalyzing the dismutation of the superoxide, into water and hydrogen peroxide. Ultimately, catalase, glutathione peroxidase and glutathione reductase dissociate hydrogen peroxide to oxygen and water [11]. Because of these enzymes action, the steady-state concentration of intracellular $\mathrm{H}_{2} \mathrm{O}_{2}$ under physiological circumstances is kept in the range of 1-10 $\mathrm{nM}$. Pathologically, some extra enzymatic sources of superoxide are activated, which contribute to the formation of increased amount of $\mathrm{H}_{2} \mathrm{O}_{2}$ and in consequences other oxidative species, such as hydroxyl radicals, hypochlorous acid or peroxynitrite may be formed [12-14].

Catalase, the second main enzyme of antioxidant defense that is considered and the main regulator of hydrogen peroxide metabolism, is present in all aerobes and many aerotolerant anaerobes [15]. Recent studies pointed out that catalase may be involved in different other processes in the cell and is catalytically active in the absence of $\mathrm{H}_{2} \mathrm{O}_{2}$. In addition, it showed a low oxidase activity, which imply the fact it can catalyze oxidation of some highly reductive substrates, such as benzidine, using molecular oxygen [16].

Catalase in addition to peroxiredoxins and glutathione peroxidases, plays a pivotal role in maintaining reduced steady state of $\mathrm{H}_{2} \mathrm{O}_{2}$ concentration, which permits to keep the cell homeostasis and adapts it to stress. It is commonly admitted that peroxiredoxins and glutathione peroxidases are essentially responsible for the removal of $\mathrm{H}_{2} \mathrm{O}_{2}$ at low concentration, although catalase is decisive at higher $\mathrm{H}_{2} \mathrm{O}_{2}$ concentrations [17].

The stated mechanisms imply the fact that both enzymes constitute an important defense mechanism against oxidative stress. There is insufficient information in literature regarding SOD and catalase assessment in retinal pathologies. Meanwhile, there are no data regarding the role of these markers and diagnostical value in $H R$.

The objective of the study was to evaluate the role of SOD and catalase in the pathogenesis of HR and establish their diagnostic value.

\section{Material and Methods Study design}

The study was approved by the Research Ethics Committee (12.02.2018) of the Nicolae Testemitanu State University of Medicine and Pharmacy, Chisinau, Republic of Moldova.

The patients included in the study, $38(42.2 \%)$ males and 52 $(57.8 \%)$ females, with a mean age of $59.79 \pm 12.29$ years (range: 38-88) were divided in three groups according to the KeithWagner-Barker classification of HR based on fundus examination, as follows: group 1 (GI): 36 patients with $I^{\text {st }}$ grade of HR, i.e., with a slight constriction of retinal arterioles; group 2 (GII): 35 patients with $2^{\text {nd }}$ grade of HR with the same manifestation as in GI plus focal narrowing of retinal arterioles and AV nicking; group 3 (GIII): 19 patients with $3^{\text {rd }}$ grade of HR with the same as in GII + flameshaped hemorrhages + cotton-wool spots + hard exudates. In the research were not included patients from the fourth group: the same as in GIII + optic disc swelling [2]. All the participants in the study signed an informed consent.

\section{Patient selection}

In the study, we enrolled hypertensive patients who came for a consultation at the Ovisus Medical Center in the period 20182019 and who, for the first time, were diagnosed with HR, confirmed after a detailed specific ophthalmological investigation: determination of visual acuity, autorefracto-keratometry, perimetry, anterior and fundus biomicroscopy, ultrasonography, tonometry, gonioscopy, optical coherence tomography (OCT) of the macular area and the papilla of the optic nerve.

Subjects that received antihypertensive or any other drug that can discredit the results of the research were excluded from the study. Also, the patients with metabolic disorders like diabetes and severe obesity, with renal and neurological pathologies, severe somatic comorbidities, antecedent ocular trauma, optic nerve atrophies of different genesis and ocular associated diseases: glaucoma, diabetic retinopathy, acute and chronic inflammatory processes, uveitis, were expelled.

\section{Sample collection}

Venous blood samples $(5 \mathrm{ml})$ were collected and centrifuged, with a further separation of serum. Tear samples were collected from the tear lake inside the lateral conjunctival sac of the inferior fornix with microcapillary tubes. Serum and tear were dispensed into Eppendorf microtubes and frozen (

\section{$-40^{\circ} \mathrm{C}$ ) until}

\section{Biochemical analysis}

Serum and tear SOD levels were assessed using the Dubinina E. E. and Matyushin B. N. method in the modification of Gudumac V. et al. [18-20], based on SOD capacity to inhibit the nitro blue tetrazolium salt (NBT) reduction in the system that contains phenazine methosulfate and NADH. Following the reduction of NBT, blue-colored nitroformazan is formed, the intensity of which coloration is proportional to the amount of reduced NBT. The degree of inhibition of this process depends on the SOD activity. Enzyme activity is reported in $\mathrm{u} / \mathrm{mL}$ for both serum and tear samples.

Catalase activity in serum and tear was determined according to Koroliuk M. in the modification of Gudumac V., et al. [18] and was based on the property of the enzyme to catalyze the cleavage of $\mathrm{H}_{2} \mathrm{O}_{2}$ to $\mathrm{H}_{2} \mathrm{O}$ and $\mathrm{O}_{2}$. Hydrogen peroxide forms a yellow compound with ammonium molybdate. In the reaction process, as the $\mathrm{H}_{2} \mathrm{O}_{2}$ decomposes, the mixture discolors. The degree of discoloration over a period correlates with the activity of the enzyme and is estimated spectrophotometrically. The results for catalase activity were expressed in $\mu \mathrm{M} / \mathrm{L}$.

\section{Statistical analysis}

The obtained data were processed using SPSS 23.0 Software. Descriptive statistical methods were used in order to calculate the median and lower and upper quartiles - Me (LQ, UQ), interquartiles range (IQR). Kolmogorov-Smirnov and Shapiro-Wilk normality tests were used to analyse data distribution. The homogeneity of variance was determined by Levene's test. The groups were compared using the non-parametric Kruskal-Wallis and Mann-Whitney tests. Correlation analysis was performed 
using Spearman correlation test. A $p<0.05$ was considered statistically significant.

\section{Results}

Tear activity of SOD was statistically significantly lower than in serum in all studied groups by $25 \%$. A significant weak positive correlation was attested between tear and serum SOD levels $(r=0.336, p=0.001)$.

Was established a statistically significant difference of SOD in serum ( $p=0.035)$ and tear $(p=0.027)$ between groups, the values decreasing in both cases as the HR progressed (Table 1).

In paired group comparisons, the serum SOD level in GII diminished compared to $\mathrm{Gl}(-1 \% ; 1451.40 \mathrm{u} / \mathrm{ml}$ (IQR 199.73) vs. $1467.37 \mathrm{u} / \mathrm{ml}$ (IQR 187.37), $\mathrm{p}=1.0$ ), along with the numbers in GIII compared to GII (-7\%; $1352.86 \mathrm{u} / \mathrm{ml}$ (IQR 218.37) vs. $1451.40 \mathrm{u} / \mathrm{ml}$ (IQR 199.73), $p=0.137)$. Statistically significant differences were observed between groups I and III (1467.37 u/ml (IQR 187.37) vs.1352.86 u/ml (IQR 218.37), $\mathrm{p}=0.032$ ) (Figure 1).

The SOD levels in tear showed similar tendency, being alleviated in GII in comparison with GI $(-6 \% ; 1057.52 \mathrm{u} / \mathrm{ml}$ (IQR 230.09) vs. $1123.89 \mathrm{u} / \mathrm{ml}$ (IQR 219.03), $\mathrm{p}=0.228$ ), as well as in GIII compared to GII (-10\%; $942.48 \mathrm{u} / \mathrm{ml}$ (IQR 223.0) vs. $1057.52 \mathrm{u} / \mathrm{ml}$ (IQR 230.09), $p=0.848$ ). Statistically significant differences were attested between groups III and I (942.48 u/ml (IQR 223.0) vs $1123.89 \mathrm{u} / \mathrm{ml}$ (IQR 219.03), $\mathrm{p}=0.031$ ).

In both researched fluids, the SOD activity showed a significant, weak strength, negative correlation with the degree of $H R$ ( $r=-0.246, p=0.019$ in serum $/ r=-0.284, p=0.007$ in tear).

Tear activity of catalase was statistically significantly lower than in serum by $30 \%$ in all studied groups $(p=0.033)$. There were no differences in catalase content in serum $(p>0.05)$ between the groups. We noted a trend of catalase activity increase in the serum of patients as HR progressed. Catalase level in GII (+3\%; 33.03 $\mu \mathrm{M} / \mathrm{L}$ (IQR 10.81) increased vs. GI $(32.20 \mu \mathrm{M} / \mathrm{L}$ (IQR 11.30)), as well as in patients in GIII compared vs. GII (+3\%; $34.23 \mu \mathrm{M} / \mathrm{L}$ (IQR 15.16) vs. $33.03 \mu \mathrm{M} / \mathrm{L}$ (IQR 10.81)). Catalase activity in serum did not show a correlation with HR degree $(r=0.143 ; p=0.177)$.

In the tear, the catalase values were $22.07 \mu \mathrm{M} / \mathrm{L}$ (IQR 10.40) in the $1^{\text {st }}$ group, $24.77 \mu \mathrm{M} / \mathrm{L}$ (IQR 6.61) $(+12 \%, p=0.023)$ in the $I^{\text {nd }}$ group and $26.13 \mu \mathrm{M} / \mathrm{L}(\mathrm{IQR} 7.06)(+6 \%, \mathrm{p}=0.839)$ in the $\mathrm{II}^{\text {rd }}$ group of patients with HR. Also, we established a significant difference between the $\mathrm{I}^{\text {st }}$ and $\mathrm{III}^{\text {rd }}$ groups, $\mathrm{p}=0.035$.

No correlations were found between serum and tear catalase levels $(r=0.125, p=0.239)$, while tear catalase showed a significant medium strength, positive correlation with the degree of $\mathrm{HR}$ $\left(r=0.261^{*}, p=0.013\right)$ (Table 2).

\section{Discussion}

HR is considered a multifaceted disorder associated with HTN. It is caused by a complex range of factors from lifestyle choice to genetic predisposition. Aside from essential and secondary HTN, because only the elevation of blood pressure does not fully reflect the extent of retinopathy, there are other factors which play a relevant role in the development of HR. The scientists linked the signs of HR with biochemical markers, such as of inflammation (an augmented high-sensitivity C-reactive protein amount), endothelial dysfunction (high von Willebrand factor (vWF) level), oxidative stress (increased serum ferritin and gamma-glutamyl transferase levels), angiogenesis (decreased adiponectin level and elevated leptin level), low birth weight, high body mass index and even alcohol consumption [5-7, 9, 21-24].

The retinal vessels are the only blood vessels detectable on routine examination, so the presence of HR will indicate also the vascular modifications occurring in other systems. But ophthalmological interpretation cannot be transposed in measurable indicators, and novel markers would substantially improve the diagnostic and guarantee a more superior stratification of the patients in groups.

Tissue damage, produced by the OS along with the inadequate antioxidant defense, is regarded as a prime cause and the most plausible mechanism of HR development in HTN. Thus, evaluation of the antioxidant enzymes in patients with HR is essential for the establishment of oxidative stress/antioxidant defense disbalance role in the pathogenesis of $H R$.

The retina was always an attractive tissue for investigation, being a complex highly metabolic organ, which has 10 distinct layers of cells and works entirely by aerobic respiration, consuming the highest amount of oxygen in comparison with any other tissue. A consequence of this fact, will result in generation of reactive species of oxygen (ROSs), like superoxide $\left(\mathrm{O}_{2}^{-} \mathbf{q}\right.$, hydroxyl radical $(\bullet \mathrm{OH})$, and hydrogen peroxide $\left(\mathrm{H}_{2} \mathrm{O}_{2}\right)$. What makes these molecules so harmful and reactive, are the unpaired electrons in $\mathrm{O}_{2}^{-}$and $\bullet \mathrm{OH}$ that would consequently damage the cell membranes and produce modification of amino acid residues and oxidation of sulfhydryl groups in proteins, breakage of peptide bonds, loss of metals in metalloproteins, depolymerization of nucleic acids, point mutations, and also would atypically oxidize polysaccharides and polyunsaturated fatty acids. $\mathrm{H}_{2} \mathrm{O}_{2}$ is less reactive, but it can interact with intracellular iron and other metalcontaining molecules, due to their capacity to easily pass the cell membrane, further generating more $\bullet \mathrm{OH}[15,25]$.

The retinal OS can be triggered both by endogenous and exogenous factors. The largest contribution of superoxide to the intracellular space is due to mitochondrial respiration. Hypoxia or any other disbalances in mitochondrial function, caused by HTN or that lead to it, may disrupt oxidative phosphorylation and generate superoxide anions. Another source of superoxide is NADPH oxidase, which markedly reinforces the oxidant capacity of the retina in the extracellular space [26]. Also, due to radiation damage caused by the light, a series of amino acids, such as tyrosine, histidine, cysteine and methionine can generate oxidative intermediates.

Table 1. SOD and catalase levels in serum and tear per grade of HR

\begin{tabular}{|c|c|c|c|c|}
\hline \multirow{3}{*}{$\begin{array}{l}\text { Kruskal- } \\
\text { Wallis }\end{array}$} & \multicolumn{2}{|c|}{$S O D, M e(L Q, \cup Q)$} & \multicolumn{2}{|c|}{ Catalase, Me (LQ, UQ) } \\
\hline & serum $(\mathrm{u} / \mathrm{ml})$ & tear $(\mathrm{u} / \mathrm{ml})$ & serum $(\mu \mathrm{M} / \mathrm{L})$ & tear $(\mu \mathrm{M} / \mathrm{L})$ \\
\hline & $\mathrm{p}=0.035$ & $p=0.027$ & $p=0.362$ & $p=0.033$ \\
\hline \multirow{3}{*}{ GI } & 1467.37 & 1123.89 & 32.20 & 22.07 \\
\hline & $(1343.54,1530.62)$ & $(974.55,1193.58)$ & $(27.25,38.55)$ & $(15.35,25.75)$ \\
\hline & $100 \%$ & $100 \%$ & $100 \%$ & $100 \%$ \\
\hline & 1451.40 & 1057.52 & 33.03 & 24.77 \\
\hline \multirow[t]{3}{*}{ GII } & $(1315.58,1515.31)$ & $933.63,1163.72)$ & $(29.58,40.39)$ & $(21.47,28.08)$ \\
\hline & $99 \%$ & $94 \%$ & $103 \%$ & $112 \%$ \\
\hline & 1352.86 & 942.48 & 34.23 & 26.13 \\
\hline \multirow[t]{2}{*}{ GIII } & $(1212.92,1431.29)$ & $(98.23,1121.24)$ & $(29.43,44.59)$ & $(20.57,27.63)$ \\
\hline & $92 \%$ & $84 \%$ & $106 \%$ & $118 \%$ \\
\hline
\end{tabular}



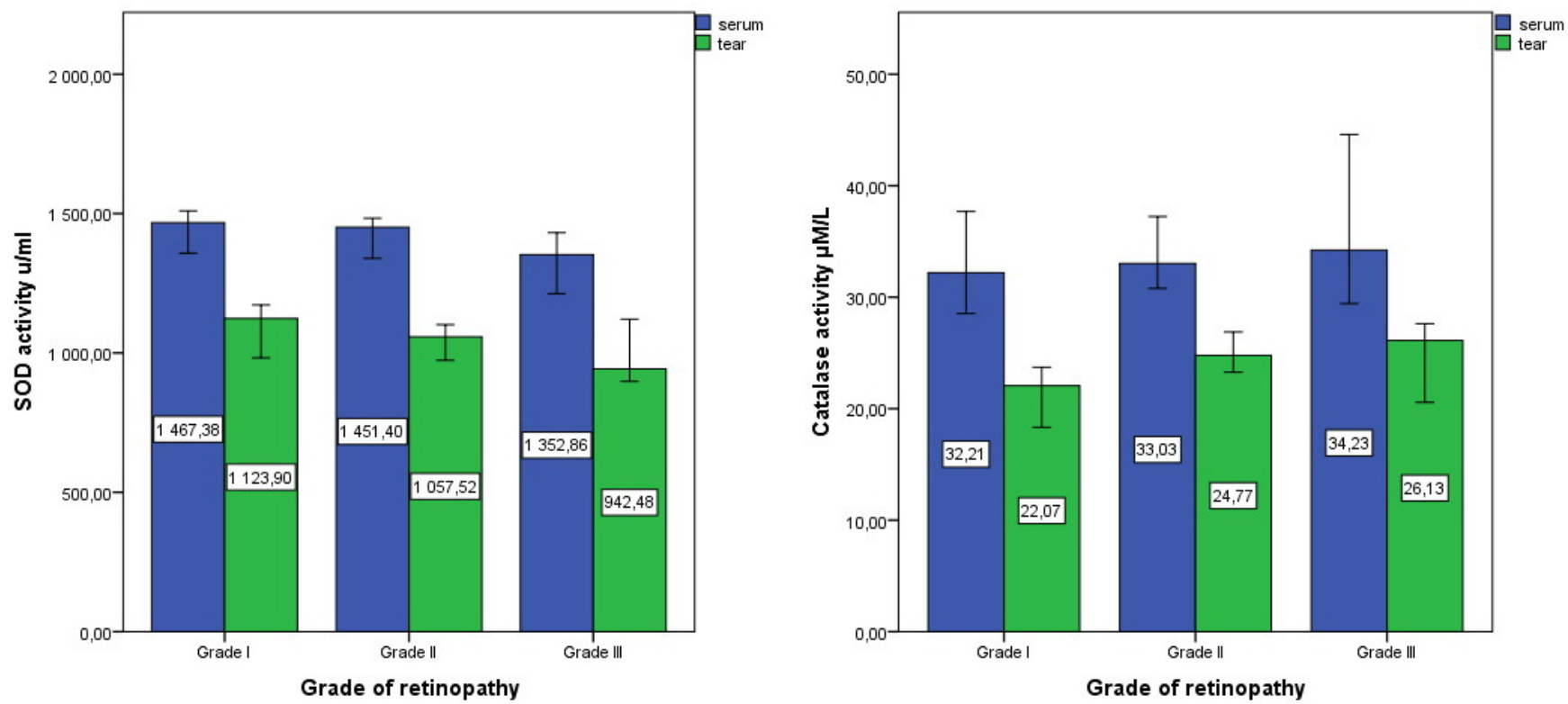

Figure 1. Serum and tear levels of SOD and catalase in patients with different grade of HR.

Table 2. Correlation of SOD and catalase levels in serum and tear with the grade of HR

\begin{tabular}{|c|c|c|}
\hline & $S O D$ & Catalase \\
\hline & in serum in tear & in serum in tear \\
\hline Correlation coefficient & $-0.246^{*}-0.284^{* *}$ & $0.143 \quad 0,261^{*}$ \\
\hline $\begin{array}{c}\text { Retinopathy Statistical significance, } 2- \\
\text { tailed }(p)\end{array}$ & 0.019 & 0.177 \\
\hline
\end{tabular}

Differences between groups and p value: ${ }^{*}<0.05 ;{ }^{* *}<0.01$.

Some up-to-date studies remarked that a respiratory mechanism in photoreceptor outer segments could contribute to extracellular ROSs. The rod outer segments of the retina that are phagocytized by retinal pigment epithelial (RPE) cells are highly susceptible to free radical damage by lipid peroxidation because of their high content of polyunsaturated fatty acids as docosahexaenoic acid (DHA). Enhanced ROSs levels are harmful and may lead to phototransduction impairment and disruption to cellular function of the retina and the RPE. The antioxidative enzymes, that will be discussed later - superoxide dismutase and catalase, minimized damage to the RPE [26].

ROSs also come from exogenous sources as a result of our lifestyle and environment. Can be mentioned as contributing factors - pollution, alcohol, tobacco smoke, heavy metals, transition metals, industrial solvents, pesticides, certain drugs like halothane, paracetamol, and radiation $[26,27]$.

Disregarding of how HTN evolves, ROSs are still a major and fundamental element in the pathogenesis of HR. Persistently enhanced levels of HTN generate an elevation in ROSs and disturb the frail stability in the retina, favoring cytotoxicity and tissue damage, that are noticed via fundoscopy, which allows to classify the extent and progression of $\operatorname{HR}[26,27]$.

Our results have shown a decreased antioxidant activity of SOD and an increased one of catalase, that might be interpreted as a cell defense mechanism against a higher OS. Possibly, the decrease of SOD activity, established by us, conditioned the increase of ROS production and subsequently of hydrogen peroxide. As a result, the need for detoxification of $\mathrm{H}_{2} \mathrm{O}_{2}$ induced the increase of catalase activity. In this order we might stipulate that the impact of OS upon the development of HR onset was proved.

During time, multiple types of SOD have been mentioned and all of them provide an essential defense system for the cells. SOD3, an extracellular SOD, that can be detected also unbound in serum and intracellularly, catalyzes the dismutation of superoxide in the extracellular matrix and can be found in almost all tissue at varying degrees. It also has and a regulatory role by influencing the proliferation, survival and apoptosis, by modulating the membrane-bound receptors, as tyrosine kinases receptors (RTKs), that are involved in the production of proangiogenic factors. In this situation, SOD3 acts like a protective shield, preventing the ROSs harmful effects on these receptors. SOD1 and SOD2 are localized in the cytosol and mitochondria [11].

Some recent studies have underlined constantly reduced levels of SOD3 in diabetic retinopathy, of SOD2 in chronic renal failure and acute ischemic stroke [28-30]. At the same time the reports of SOD activity evaluation in HTN are contradictory, yielding various results from increased to decreased levels $[20,29]$. On the other hand, increased catalase expression was determined in HTN, various types of cancer, also a polymorphism in the promoter region of catalase is associated with high blood pressure levels [12, $13,31]$. Catalase deficiency was identified in diabetes, anemia, Wilson disease, bipolar disorder and schizophrenia [32].

Experimental evidence highlighted that ROSs, and more specifically the superoxide anion $\left(\mathrm{O}_{2}^{-} \boldsymbol{9}\right.$, play a decisive role in the genesis of HTN through mechanisms that are not fully understood.

Usually, generation of ROSs is tightly regulated and they are preserved at low concentration. They serve as signaling molecules, that provide the integrity of the vessels, as a result of their involvement in the modulation of endothelial function and vascular contraction-relaxation balance. Pathologically, augmented amount of the ROS induces endothelial dysfunction, that is considered to be an essential pathological mechanism in the evolution of HTN. Furthermore, elevated ROSs levels stimulate vascular smooth muscular cells growth, increased contractility, 
invasion of the monocytes, lipid peroxidation, inflammation and increased deposition of extracellular matrix proteins, all of which are crucial factors in hypertensive vascular damage and causes of the clinical signs of HR appearance [33-35].

Lob et al., in order to clarify the mechanism by which $\mathrm{O}_{2}{ }^{-}$ contributes to HTN, used Cre-lox technology to create mice with a target deletion of SOD3. The study results showed that SOD3 in the vascular smooth muscle, regardless of enhanced vascular $\mathrm{O}_{2}{ }^{-}$ levels, had no effect on blood pressure, neither at baseline nor as a result to angiotensin II (AngII) stimulation, and also did not increase the inflammatory response to Angll. Also, the depletion of SOD3 in both circumventricular organs (CVOs) and in the vascular smooth muscle showed similar effect to depletion in CVOs alone. The results underlined the fact that SOD3 in the CNS presumably have a more significant role in modulation of blood pressure than SOD3 in the vasculature [28].

Gomez-Marcos et al. detected in their study that HTN was linked with a decrease of serum SOD [36]. This decline suggests a deficit in antioxidant defense mechanisms, that subsequently would affect the ability of the hypertensive patients to eliminate the circulating superoxide anion and determine an elevation in vascular damage, induced by ROS. They concluded that a decreased level of SOD in serum is associated with enhanced vascular damage. This research is sustained by the results of Kumar et al. who highlighted in their study that the concentrations of both catalase and glutathione peroxidase in red blood cells were low in uncontrolled hypertensives but did not reach statistically significant levels, however there was a significant decrease in SOD concentration [37].

Contrary to previous results, Labios et al. observed an increase in SOD and catalase activities in leucocyte lysates from hypertensive patients. They supposed the general idea of a 'vicious circle' among HTN and ROS, that could be explained by the fact that an elevation of ROS does not only play a crucial role in the development of HTN, but it can be generated by HTN itself [13]. So, long-term HTN would ultimately produce an irreversible endothelial dysfunction mostly due to self-sustaining ROS production.

Only a few up-to-date studies pointed out explicitly the involvement of OS in the development of HR. Up to now, only two markers of OS have been analyzed. Karaca et al. highlighted an elevated level of serum $\mathrm{y}$-glutamyl transferase (GGT) in HR, that is an enzyme with a pivotal role in glutathione homeostasis and is crucial in preserving sufficient concentrations of intracellular glutathione in order to defend the cells against oxidants [9]. The second study, conducted by Coban et al. emphasized the fact that there is a correlation between HR and high ferritin level in serum, that might be related to an augmented level of OS due to iron involvement in Fenton reaction [10].

Our results are quite similar to those mentioned above. Moreover, as far as we know, our research underlined for the first time the decrease of serum and tear SOD levels and the augmented levels of serum and tear catalase in HR. The study pointed out that in hypertensive patients with HR, in both researched fluids, SOD activity showed a significant weak strength, negative correlation with the degree of $H R(r=-0.246, p=0.019$ in serum $/ r=-0.284, p=0.007$ in tear). Also, a significant weak positive correlation was attested between serum and tear SOD levels $(r=0.336, p=0.001)$. However, even though no correlation with serum catalase was found, tear catalase showed a significant weak strength, positive correlation with the degree of $H R \quad(r=0.261$, $\mathrm{p}=0.013$ )

Hence, the low serum and tear SOD levels and high serum and tear catalase activity in HR and their correlation with the severity of $H R$ implies that oxidative stress may be attributed to the mechanism of HR progress. The correlation between serum SOD and tear SOD implies the necessity for a more precise interpretation of the decrease of this biomarker in both of the fluids, and the fact that might and should be interpreted in the context of clinical manifestation of HR.

We must also be aware of the evidence that the auto modulation of the retinal circulation is disrupted once the blood pressure (BP) increased. In addition, enhanced BP by itself does not explicitly clarify the stage of $\operatorname{HR}[6,9,38,39]$. It was even affirmed that in spite of the constancy of increased blood pressure, a resolution of the retinopathy was observed [40]. In our study, taking under the consideration the evidence that the BP levels in all three groups were mostly similar, SOD levels progressively decreased while catalase activity increased gradually with HR change, we can conclude that these enzymes can be used as a marker for the monitoring of HR progression.

\section{Conclusions}

This study expands on previous research on understanding how OS contributes to HR. Biochemical evidence suggests that oxidative damage of the retina is engaged in the origin of HR. The article examined a number of issues, such as the reason why retina research is essential, OS relation to $\mathrm{HR}$, and in what manner retina defends itself from overloading the anti-oxidant defense system.

A progressive significant decrease in both serum and tear SOD levels and a tendency to increase catalase activity were identified as HR advanced. The enhancement in the severity of HR correlates with decreased SOD activity in tear and serum and increased catalase level in tear and does not correlate with increased catalase in serum. The results are indicating that each of the studied enzymes could be used as a marker of HR progression and as a predictor of extensive retinal damage, considering the idea that they concomitantly change in both the eye and serum. Additional studies are necessary to finally identify the role of the oxidative stress and antioxidant system in the development of HR and also to determine more precisely the threshold values of SOD and catalase activities, that would permit their use for an easier stratification of patients in groups.

\section{Limitations}

This study has several limitations. SOD and catalase in our study are two markers, changes of which cannot fully be explained solely by HTN, HR or both of them simultaneously. Moreover, our results cannot clarify the issue whether the decreased SOD levels and increased catalase activity anticipate the development of retinopathy or contrarily is a repercussion.

Also, it is quite challenging to detect the long-term natural history of HTN for the reason that antihypertensive medication is often administrated to prevent cardiovascular disease. In such cases, the true effect of different factors on natural modulation of blood pressure can be dissimulated by the effects of antihypertensive drugs. Nonetheless, our study was conducted on patients that were not taking any antihypertensive treatment at 
that moment or any other treatment that could compromise the results.

Finally, this research has been carried out at a single hospital. We must be precautious in generalizations made across different hospitals and countries.

\section{Funding}

Doctoral grant offered by Ministry of Education, Culture and Research of the Republic of Moldova.

\section{Conflict of interest}

No conflicts of interest are declared.

\section{Ethical approval}

The study protocol was approved by the Research Ethics Committee of the Nicolae Testemitanu State University of Medicine and Pharmacy (12.02.2018). All procedures performed in studies involving human participants were in accordance with the ethical standards of the institutional research committee and with the 1964 Declaration of Helsinki and its later amendments or comparable ethical standards.

\section{References}

1. Bromfield S, Muntner P. High blood pressure: the leading global burden of disease risk factor and the need for worldwide prevention programs. Curr Hypertens Rep 2013; 15(3): 134-136. https://doi:10.1007/s11906-013-0340-9.

2. Oparil $S$, Acelajado $M C$, Bakris GL, Berlowitz DR, Cífková $R$, Dominiczak AF, et al. Hypertension. Nat Rev Dis Primers 2018; 4: 18014. https://doi:10.1038/nrdp.2018.14.

3. Modi P, Arsiwalla T. Hypertensive Retinopathy. 2021 Jul 10. In: StatPearls. Treasure Island (FL): StatPearls Publishing; 2021. https://pubmed.ncbi.nlm.nih.gov/30252236/.

4. Kabedi NN, Mwanza JC, Lepira FB, Kayembe TK, Kayembe DL. Hypertensive retinopathy and its association with cardiovascular, renal and cerebrovascular morbidity in Congolese patients. Cardiovasc J Afr 2014; 25(5): 228-232. https://doi:10.5830/CVJA-2014-045.

5. Erden S, Bicakci E. Hypertensive retinopathy: incidence, risk factors, and comorbidities. Clin Exp Hypertens 2012; 34(6): 397-401. https://doi:10.3109/10641963.2012.663028.

6. Chatterjee S, Chattopadhyay S, Hope-Ross M, Lip PL. Hypertension and the eye: changing perspectives. J Hum Hypertens 2002; 16(10): 667675. https://doi:10.1038/sj.jhh.1001472.

7. Pavlovschi E. Emerging concepts of the ocular molecular-metabolic effects of the hypertension. In: XXI ISPC International Trends in Science and Technology, Warsaw, Poland: RS Global Sp. z O.0. 2020; 48-51. https://conferences.rsglobal.pl/index.php/conf/catalog/view/12/19/3 59-1.

8. Pavlovschi E., Stratulat S., Ambros A., Borovic, D., Tagadiuc O., Evaluarea modificărilor markerilor OCT în retinopatia hipertensivă. In: Buletinul Academiei de Ştiințe a Moldovei. Științe Medicale. 2020: (1(65)): 295-299. Romanian. https://ibn.idsi.md/ro/vizualizare_articol/115082/datacite.

9. Karaca $\mathrm{M}$, Coban $\mathrm{E}$, Felek $\mathrm{R}$, Unal $\mathrm{M}$. The association of oxidative stress with hypertensive retinopathy. Clin Exp Hypertens 2013; 35(1): 16-19. https://doi:10.3109/10641963.2012.685535.

10. Coban E, Alkan E, Altuntas S, Akar Y. Serum ferritin levels correlate with hypertensive retinopathy. Med Sci Monit 2010; 16(2): CR92-CR95. https://pubmed.ncbi.nlm.nih.gov/20110920.

11. Akeo K, Hiramitsu T, Kanda T, Karasawa $Y$, Okisaka S. Effects of Superoxide Dismutase and Catalase on Growth of Retinal Pigment Epithelial Cells in vitro following Addition of Linoleic Acid or Linoleic
Acid Hydroperoxide. Ophthalmic Res 1996; 28(1): 8-18. https://doi:10.1159/000267868.

12. Gebicka L, Krych-Madej J. The role of catalases in the prevention/promotion of oxidative stress. J Inorg Biochem 2019; 197 110699. https://doi:10.1016/j.jinorgbio.2019.110699.

13. Labiós M, Martínez M, Gabriel F, Guiral V, Dasi F, Beltrán B, et al. Superoxide dismutase and catalase anti-oxidant activity in leucocyte lysates from hypertensive patients: effects of eprosartan treatment. $J$ Renin Angiotensin Aldosterone Syst 2009; 10(1): 24-30. https://doi:10.1177/1470320309104067.

14. Masuda T, Shimazawa M, Hara H. Retinal Diseases Associated with Oxidative Stress and the Effects of a Free Radical Scavenger (Edaravone). Oxid Med Cell Longev 2017; 2017: 9208489. https://doi.org/10.1155/2017/9208489.

15. Brioukhanov AL, Netrusov Al. Catalase and superoxide dismutase: distribution, properties, and physiological role in cells of strict anaerobes. Biochem (Mosc) 2004; 69(9): 949-962. https://doi:10.1023/b:biry.0000043537.04115.d9.

16. Gebicka L, Krych-Madej J. The role of catalases in the prevention/promotion of oxidative stress. J Inorg Biochem 2019; 197: 110699. https://doi:10.1016/j.jinorgbio.2019.110699.

17. Kodydková J, Vávrová L, Kocík M, Žák A. Human catalase, its polymorphisms, regulation and changes of its activity in different diseases. Folia Biol (Praha) 2014; 60(4): 153-167. https://pubmed.ncbi.nlm.nih.gov/25152049.

18. Gudumac V, Rîvneac V, Tagadiuc O, Sardari V., Rîvneac E., Andronache L, et al. Metode de cercetare a metabolismului hepatic: Elaborare metodică. Chisinau: Tehnica-Info. 2012: 103-106. Romanian.

19. Matyushin B.N., Loginov A.S., Tkachev VD. Identification of superoxide scavenge activity of hepatic puncture biopsies under its chronic damage. Laboratornoe delo 1991: (7): 16-19. Russian.

20. Dubinina EE, Burmistrov SO, Khodov DA, Porotov IG. Oxidative modification of human serum proteins. A method of determining it. Vopr Med Khim 1995; 41(1): 24-26. (in Russian). https://pubmed.ncbi.nlm.nih.gov/7771084.

21. Uckaya G, Ozata M, Sonmez A, Kinalp C, Eyileten T, Bingol N, et al. Is leptin associated with hypertensive retinopathy? J Clin Endocrinol Metab 2000; 85(2): 683-687. https://doi:10.1210/jcem.85.2.6361.

22. Yilmaz MI, Sonmez A, Kilic S, Celik T, Bingol N, Pinar $M$, et al. The association of plasma adiponectin levels with hypertensive retinopathy. Eur J Endocrinol 2005; 152(2): 233-240. https://doi:10.1530/eje.1.01851.

23. Biesenbach G, Zazgornik J. High prevalence of hypertensive retinopathy and coronary heart disease in hypertensive patients with persistent microalbuminuria under short intensive antihypertensive therapy. Clin Nephrol 1994; 41(4): 211-218. https://pubmed.ncbi.nlm.nih.gov/8026113.

24. Coban E, Nizam I, Topal C, Akar Y. The association of low-grade systemic inflammation with hypertensive retinopathy. Clin Exp Hypertens 2010; 32(8): 528-531. https://doi:10.3109/10641963.2010.496519.

25. Touyz RM. Reactive oxygen species in vascular biology: role in arterial hypertension. Expert Rev Cardiovasc Ther 2003. 1(1): 91-106. https://doi:10.1586/14779072.1.1.91.

26. Bowes Rickman C, LaVail MM, Anderson RE, Grimm C, Hollyfield J, Ash J, eds. Retinal Degenerative Diseases: Mechanisms and Experimental Therapy. Switzerland: Springer International Publishing AG. 2016; 824 p. https://doi:10.1007/978-3-319-17121-0.

27. Phaniendra A, Jestadi DB, Periyasamy L. Free radicals: properties, sources, targets, and their implication in various diseases. Indian J Clin Biochem 2015; 30(1): 11-26. https://doi:10.1007/s12291-014-0446-0.

28. Lob HE, Vinh A, Li L, Blinder Y, Offermanns S, Harrison DG. Role of vascular extracellular superoxide dismutase in hypertension. Hypertension 2011; 232-239. https://doi:10.1161/HYPERTENSIONAHA.111.172718. 
29. Vaziri ND, Dicus M, Ho ND, Boroujerdi-Rad L, Sindhu RK. Oxidative stress and dysregulation of superoxide dismutase and NADPH oxidase in renal insufficiency. Kidney Int 2003; 63(1): 179-185. https://doi:10.1046/i.1523-1755.2003.00702.x.

30. Pong K. Oxidative stress in neurodegenerative diseases: therapeutic implications for superoxide dismutase mimetics. Expert Opin Biol Ther 2003; 3(1): 127-139. https://doi:10.1517/14712598.3.1.127.

31. Jiang $Z$, Akey JM, Shi J, Xiong $M$, Wang $Y$, Shen $Y$, et al. A polymorphism in the promoter region of catalase is associated with blood pressure levels. Hum Genet 2001; 109(1): 95-98. https://doi:10.1007/s004390100553.

32. Nandi A, Yan LJ, Jana CK, Das N. Role of Catalase in Oxidative Stressand Age-Associated Degenerative Diseases. Oxid Med Cell Longev 2019; 2019: 9613090. https://doi.org/10.1155/2019/9613090.

33. Karaca M, Coban E, Ozdem S, Unal M, Salim O, Yucel O. The association between endothelial dysfunction and hypertensive retinopathy in essential hypertension. Med Sci Monit 2014; 20: 78-82. https://doi:10.12659/MSM.889659.

34. DellaCroce JT, Vitale AT. Hypertension and the eye. Curr Opin Ophthalmol 2008; 19(6): 493-498. https://doi:10.1097/ICU.0b013e3283129779.

35. Wong TY, Mitchell P. The eye in hypertension. Lancet 2007; 369(9579): 425-435. https://doi:10.1016/S0140-6736(07)60198-6.

36. Gómez-Marcos MA, Blázquez-Medela AM, Gamella-Pozuelo L, RecioRodriguez JI, García-Ortiz L, Martínez-Salgado C. Serum Superoxide Dismutase Is Associated with Vascular Structure and Function in Hypertensive and Diabetic Patients. Oxid Med Cell Longev 2016; 2016: 9124676. https://doi.org/10.1155/2016/9124676.

37. Kumar KV, Das UN. Are free radicals involved in the pathobiology of human essential hypertension? Free Radic Res Commun 1993; 19(1): 59-66. https://doi:10.3109/10715769309056499.

38. Prakash D. Target organ damage in newly detected hypertensive patients. J Family Med Prim Care 2019; 8(6): 2042-2046. https://doi:10.4103/jfmpc.jfmpc 23119.

39. Redón J, Oliva MR, Tormos C, Giner V, Chaves J, Iradi A, et al. Antioxidant activities and oxidative stress byproducts in human hypertension. Hypertension 2003; 41(5): 1096-1101. https://doi:10.1161/01.HYP.0000068370.21009.38.

40. Lowenthal MN, Zimlichman R. Resolution of hypertensive retinopathy despite persistent high diastolic pressure. South Med J 1993; 86(2): 190-193. https://doi:10.1097/00007611-199302000-00010.

Authors:

Ecaterina Pavlovschi - PhD fellow, Instructor, Department of Biochemistry and Clinical Biochemistry, Nicolae Testemitanu State University of Medicine and Pharmacy, Chisinau, Republic of Moldova. https://orcid.org/0000-0003-0385-4805.

Djina Borovic - MD, PhD, Department of Ophthalmology, Ovisus Medical Private Center, Chisinau, Republic of Moldova. https://orcid.org/00000001-9876-3628.

Valeriana Pantea - Researcher, Laboratory of Biochemistry, Nicolae Testemitanu State University of Medicine and Pharmacy, Chisinau, Republic of Moldova. https://orcid.org/0000-0002-8835-6612.

Olga Tagadiuc - MD, PhD, Chair of Biochemistry and Clinical Biochemistry Department, Nicolae Testemitanu State University of Medicine and Pharmacy, Chisinau, Republic of Moldova. https://orcid.org/0000-0002$\underline{5503-8052}$. 